\title{
Knowledge among physical education professionals about poliomyelitis and post-poliomyelitis syndrome: a cross-sectional study in Brazil
}

\author{
Claudio Andre Barbosa \\ de Lira' \\ Taíza Márcia de \\ Almeida Alves' \\ Luiz Fernando \\ Peixinho-Pena \\ Bolivar Saldanha Sousa ${ }^{3,4}$ \\ Marcos Gonçalves \\ de Santana' \\ Sandra Aparecida \\ Benite-Ribeiro' \\ Marilia dos Santos Andrade 2 \\ Rodrigo Luiz Vancini² \\ 'Setor de Fisiologia Humana e do \\ Exercício, Universidade Federal \\ de Goiás, Câmpus Jataí, Jataí, \\ ${ }^{2}$ Departamento de Fisiologia, \\ Universidade Federal de São Paulo, \\ São Paulo, Brazil; ${ }^{3}$ Faculdade de \\ Ciências Médicas da Santa Casa de \\ São Paulo, São Paulo, Brazil; ${ }^{4}$ Instituto \\ Israelita de Ensino e Pesquisa Albert \\ Einstein, São Paulo, Brazil
}

This article was published in the following Dove Press journal:

Degenerative Neurological and Neuromuscular Disease

8 August 2013

Number of times this article has been viewed

Background: Post-poliomyelitis syndrome is a clinical condition that can affect poliomyelitis survivors with the onset of new symptoms several years after the acute disease. These symptoms include new muscular weakness, fatigue, pain, onset or aggravation of muscle atrophy, muscle cramps, onset or aggravation of pre-existing difficulties in accomplishing daily life activities, cold intolerance, sleep disorders, dysphonia or dysphagia, and respiratory deficiency. The treatment of post-poliomyelitis syndrome requires a multiprofessional health team because the rehabilitation procedures include lifestyle changes, physiotherapy, avoidance of secondary complications, and physical exercise. As physical exercise is prescribed by physical education professionals, the assessment of knowledge about post-poliomyelitis syndrome among these professionals is very relevant. The aim of this study was to evaluate poliomyelitis and post-poliomyelitis syndrome knowledge among physical education professionals in Brazil.

Methods: We invited participants with an academic degree in physical education $(n=217)$ to participate in this study. A self-administered survey (30 questions) was designed to probe knowledge about poliomyelitis and post-poliomyelitis syndrome. From the survey, we created a questionnaire to evaluate the performance of the professionals. The questionnaire was composed of 20 questions and a score was provided, varying from 0 (totally uninformed) to 20 (well informed).

Results: Approximately $73 \%$ of surveyed participants had never heard of post-poliomyelitis syndrome, and only $19.4 \%$ had received information about the disease. Among those surveyed, $61.8 \%$ did not know whether restriction of physical activities was warranted for people with poliomyelitis sequelae, and only $32.3 \%$ knew that physical exercise (especially intense exercise) should be limited for patients with sequelae of paralytic poliomyelitis.

Conclusion: The findings of the present study indicate a critical need for improvement of knowledge about post-poliomyelitis syndrome among Brazilian physical education professionals.

Keywords: post-poliomyelitis syndrome, knowledge, athletic trainers, physical education

\section{Introduction}

Many people with a history of poliomyelitis report late-onset neuromuscular symptoms and a decline in their functional abilities. These late-onset symptoms are referred to as post-poliomyelitis syndrome (PPS), and include new or increased muscle weakness, fatigue, muscle and joint pain, muscle cramps, and cold intolerance. ${ }^{1}$ The current pathophysiologic hypothesis is that PPS is caused by the premature metabolic exhaustion of chronically overloaded motor neurons. ${ }^{2-6}$ These new symptoms also

Correspondence: Claudio Andre Barbosa de Lira

Setor de Fisiologia Humana e do

Exercício, Universidade Federal de Goiás, Rod BR 364, km 192, Parque Industrial 3800, CEP 7580 I-6I5, Jataí, Goiás, Brazil Email andre.claudio@gmail.com 
cause progressively increasing difficulties with physical functions, such as walking, standing, climbing stairs, and other mobility-related activities of daily life. ${ }^{7,8}$

Although the number of new cases of poliomyelitis has dropped dramatically due to the introduction of an effective vaccination program, there are still approximately 20 million people with poliomyelitis sequelae ${ }^{9}$ who may develop PPS and need rehabilitation interventions. In addition, some African and Asian countries are registering new cases of poliomyelitis. According to the World Health Organization, in 2013, only three countries (Afghanistan, Nigeria, and Pakistan) remain polio-endemic and eight are affected by importations of the virus (Central African Republic, Côte d'Ivoire, Kenya, Liberia, Mali, Niger, Somalia, and Uganda). ${ }^{10}$ Therefore, the future perspective is for a continued or potentially increased need for treatment of people with PPS.

Treatment of PPS requires a multiprofessional health team and is based on lifestyle changes, physiotherapy, physical exercise, and avoidance of secondary complications. ${ }^{1}$ In this context, physical exercise is an important tool for rehabilitation of patients with PPS. However, physical exercise is beneficial for these patients only if an appropriate strategy is determined. Although the benefits of regular physical exercise are without question, ${ }^{11}$ the prescription of exercise for people with sequelae of paralytic poliomyelitis has been the focus of an extensive debate. Health professionals believe that physical exercise in these patients, especially intense physical exercise, may be harmful because the resultant metabolic overload on motor units that physical exercise induces can precipitate development of PPS. ${ }^{1}$ However, physical exercise is a useful tool for the treatment of muscle fatigue and weakness, both symptoms that are present in patients with sequelae of paralytic poliomyelitis. Therefore, current management guidelines recommend that only mild to moderate exercise should be performed to avoid metabolic overload on the giant motor units. ${ }^{1}$ In Brazil, physical exercise is prescribed by physical education professionals, so evaluation of knowledge of these professionals about the disease is substantially relevant. In addition, previous studies have shown that these professionals do not have adequate knowledge about other diseases, including acquired immune deficiency syndrome (AIDS) $)^{12}$ and epilepsy. ${ }^{13,14}$ Thus, in the present study, we evaluated the knowledge about poliomyelitis and PPS among Brazilian physical education professionals. We hypothesized that physical education professionals would not have knowledge related to PPS, such as physiopathology, patient care, and symptomatology.

\section{Materials and methods}

\section{Participants}

We invited participants from the community with an academic degree in physical education $(n=217,54$ females and 163 males, age $30.1 \pm 7.1$ years [mean \pm standard deviation]) to participate in this study using different sources of advertisement (ie, Internet, local newspapers, magazine and billboards in universities, clinics, hospitals, and gymnasiums). Inclusion criteria for participation in the study were professionals with at least an undergraduate degree in physical education. All procedures involved in this study were approved by the university ethics committee and followed the principles outlined in the Declaration of Helsinki. All participants gave their written informed consent to participate in this study.

\section{Survey}

A self-administered survey was designed to probe knowledge about poliomyelitis and PPS. The survey contained 30 items (14 about poliomyelitis and 16 about PPS) with simple, closed end-type response scales. This survey was constructed according to previous recommendations. ${ }^{15,16}$ From the survey (composed of 30 questions), we created a questionnaire using 20 questions (see Tables 1 and 2) in order to evaluate, in an objective manner, the performance of the professionals interviewed. Through the questionnaire, a score was provided, varying from 0 (totally uninformed) to 20 (well informed). For each of the 20 questions, there was a correct answer; the participant who correctly answered received 1 point and one who erred received 0 point. These 20 questions were chosen because they contain basic knowledge about poliomyelitis and PPS. Additionally, the subjects were divided into two groups, ie, those who answered "yes" and those who answered "no" to the question "Have you received information about PPS?" (Figure 1).

\section{Statistical analysis}

A descriptive statistical analysis was performed (mean, standard deviation, and absolute and relative frequencies). None of the variables presented with normal distributions according to Kolmogorov-Smirnov tests. Therefore, MannWhitney tests were used to compare scores obtained in the questionnaire between the two exposure ("yes" and "no") groups. Spearman's correlation tests were used to assess correlations between scores on the questionnaire, experience in the field, and education level. Differences were considered to be statistically significant at the level of $P<0.05$. 
Table I Answers of physical educational professionals related to poliomyelitis

\begin{tabular}{|c|c|c|c|c|}
\hline Questions & $\begin{array}{l}\text { Yes } \\
\text { n (\%) }\end{array}$ & $\begin{array}{l}\text { No } \\
\text { n (\%) }\end{array}$ & $\begin{array}{l}\text { Did not know } \\
\text { n (\%) }\end{array}$ & $\begin{array}{l}\text { Did not answer } \\
\text { n (\%) }\end{array}$ \\
\hline Have you heard about poliomyelitis? & $208(95.9)$ & $9(4.1)$ & $\mathrm{N} / \mathrm{A}$ & 0 \\
\hline Have you had information about poliomyelitis? & $125(57.6)$ & $91(41.9)$ & $\mathrm{N} / \mathrm{A}$ & $\mathrm{I}(0.5)$ \\
\hline Is poliomyelitis caused by a virus?* & I I 6 (53.5) & $17(7.8)$ & $84(38.7)$ & 0 \\
\hline $\begin{array}{l}\text { Can poliomyelitis be spread through water and/or food } \\
\text { contaminated with feces from a sick person?* }\end{array}$ & $27(12.4)$ & $76(35.0)$ & $114(52.5)$ & 0 \\
\hline Can poliomyelitis cause gastrointestinal symptoms?* & $18(8.3)$ & $49(22.6)$ & $150(69.1)$ & 0 \\
\hline $\begin{array}{l}\text { Can poliomyelitis cause neuromuscular symptoms such } \\
\text { as paralysis, paresis, muscle atrophy, and weakness?* }\end{array}$ & $190(87.6)$ & $\mathrm{I}(0.5)$ & $26(12.0)$ & 0 \\
\hline $\begin{array}{l}\text { After the acute poliomyelitis stage, can patients recover } \\
\text { functional capacity of affected structures fully or partially?* }\end{array}$ & $86(39.6)$ & $46(21.2)$ & $85(39.2)$ & 0 \\
\hline Is poliomyelitis eradicated around the world?* & $48(22.1)$ & $114(52.5)$ & $55(25.3)$ & 0 \\
\hline Is there a vaccine available to prevent poliomyelitis?* & $196(90.3)$ & $2(0.9)$ & $19(8.8)$ & 0 \\
\hline $\begin{array}{l}\text { May poliomyelitis treatment involve admission to the intensive } \\
\text { care unit due to respiratory impairment?* }\end{array}$ & $38(17.5)$ & $16(7.4)$ & $163(75.1)$ & 0 \\
\hline Are you afraid to live with a person who had poliomyelitis? & $3(1.4)$ & $211(97.2)$ & $\mathrm{N} / \mathrm{A}$ & $3(1.4)$ \\
\hline During your undergraduate course, have you had access to information & $30(13.8)$ & $183(84.3)$ & N/A & $4(1.8)$ \\
\hline $\begin{array}{l}\text { on how to handle patients with poliomyelitis in your future profession? } \\
\text { In your practice (eg, hospital, clinic, gymnasium, school), have you } \\
\text { ever provided service for people with sequelae of poliomyelitis? }\end{array}$ & $34(15.7)$ & $176(8 \mid .1)$ & N/A & $7(3.2)$ \\
\hline $\begin{array}{l}\text { Can people with sequelae of poliomyelitis perform any } \\
\text { type of physical activity?* }\end{array}$ & $163(75.1)$ & $\mathrm{I}(0.5)$ & $52(24.0)$ & $\mathrm{I}(0.5)$ \\
\hline
\end{tabular}

Note: $*$ These questions composed the questionnaire.

Abbreviation: N/A, not applicable.

\section{Results}

Participants' mean time working in physical education was $6 \pm 6$ years. Among all participants, 4.1\% $(\mathrm{n}=9)$ had a doctoral degree, $3.2 \%(n=7)$ had a master's degree, $83.4 \%$ $(n=181)$ were specialized in an exercise or sports science, and $9.2 \%(n=20)$ had an undergraduate academic degree. Areas of expertise were varied, with $0.9 \%(n=2)$ of participants having professional experience of adapted sports for people with disabilities, 4.1\% $(n=9)$ having academic/scientific research experience, $12.0 \%(n=26)$

Table 2 Answers of physical educational professionals related to post-poliomyelitis syndrome

\begin{tabular}{|c|c|c|c|c|}
\hline Questions & $\begin{array}{l}\text { Yes } \\
\text { n (\%) }\end{array}$ & $\begin{array}{l}\text { No } \\
\text { n (\%) }\end{array}$ & $\begin{array}{l}\text { Did not know } \\
\text { n (\%) }\end{array}$ & $\begin{array}{l}\text { Did not answer } \\
\text { n (\%) }\end{array}$ \\
\hline Have you heard about PPS? & $55(25.3)$ & $158(72.8)$ & N/A & $4(1.8)$ \\
\hline Have you received information about PPS? & $42(19.4)$ & $170(78.3)$ & N/A & $5(2.3)$ \\
\hline Is PPS a disease that only affects patients who have had paralytic poliomyelitis?* & $37(17.1)$ & $19(8.8)$ & $160(73.7)$ & $\mathrm{I}(0.5)$ \\
\hline Is there any restriction of intense physical activity for poliomyelitis patients?* & $70(32.3)$ & $13(6.0)$ & $134(61.8)$ & 0 \\
\hline Can people with PPS perform any type of physical activity?* & $106(48.8)$ & $3(1.4)$ & $108(49.8)$ & 0 \\
\hline $\begin{array}{l}\text { Is there a need for clinical follow-up of patients years after having been } \\
\text { affected by poliomyelitis?* }\end{array}$ & $87(40.1)$ & II (5.1) & $119(54.8)$ & 0 \\
\hline Is the most appropriate way to diagnose PPS based on symptomatology?* & $39(18.0)$ & $6(2.8)$ & $172(79.3)$ & 0 \\
\hline Is there an effective treatment for PPS, a little known disease?* & $17(7.8)$ & $19(8.8)$ & I8I (83.4) & 0 \\
\hline Is the poliovirus responsible for onset of PPS?* & $19(8.8)$ & $10(4.6)$ & $188(86.6)$ & 0 \\
\hline Is PPS considered a neuromuscular disease?* & $78(35.9)$ & $6(2.8)$ & $133(61.3)$ & 0 \\
\hline $\begin{array}{l}\text { Are the main clinical manifestations presented by PPS patients new } \\
\text { weakness, fatigue, and muscle and/or joint pain?* }\end{array}$ & $61(28.1)$ & $4(1.8)$ & $152(70.0)$ & 0 \\
\hline $\begin{array}{l}\text { Can neuromuscular symptoms of PPS occur in limbs previously } \\
\text { affected by poliomyelitis?* }\end{array}$ & $63(29.0)$ & $4(1.8)$ & $150(69.1)$ & 0 \\
\hline $\begin{array}{l}\text { Can PPS be considered a progressive neuromuscular disease, } \\
\text { presenting a slow worsening of signs and symptoms? }\end{array}$ & $46(21.2)$ & $5(2.3)$ & $166(76.5)$ & 0 \\
\hline Are you afraid to live with a person who has PPS? & $5(2.3)$ & $205(94.5)$ & $\mathrm{N} / \mathrm{A}$ & $7(3.2)$ \\
\hline $\begin{array}{l}\text { During your undergraduate course, have you had access to information } \\
\text { on how to handle PPS? }\end{array}$ & $4(1.8)$ & $203(93.5)$ & N/A & $10(4.6)$ \\
\hline $\begin{array}{l}\text { In your practice (hospital, clinic, gymnasium, school), have you ever } \\
\text { provided service for people with PPS? }\end{array}$ & $8(3.7)$ & $201(92.6)$ & N/A & $8(3.7)$ \\
\hline
\end{tabular}

Note: $*$ These questions composed the questionnaire.

Abbreviations: N/A, not applicable; PPS, post-poliomyelitis syndrome. 


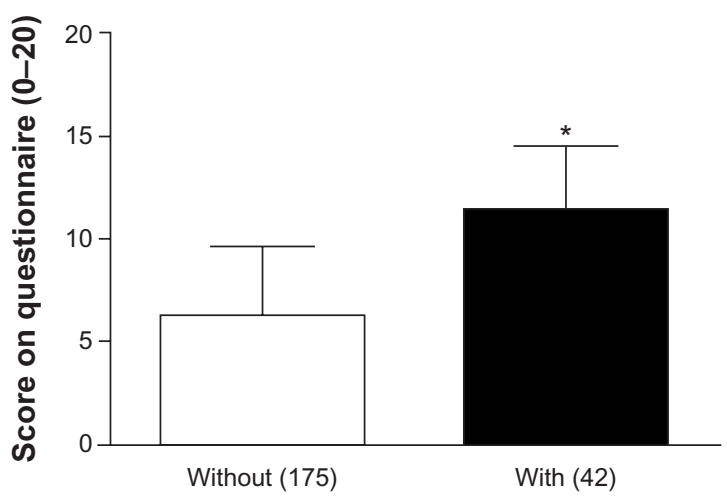

Figure I Questionnaire result (0-20) separated by physical education professionals without $(n=175)$ or with $(n=42)$ access to information about post-poliomyelitis syndrome.

Notes: Data are presented as the mean \pm standard deviation. $* P<0.0001$, MannWhitney test.

having high-performance sport experience, $43.8 \%(n=95)$ having techniques to improve general health and quality of life experience, and $23.0 \%(\mathrm{n}=50)$ having experience with physical education in schools. An additional 13.4\% $(\mathrm{n}=29)$ did not give an area of expertise and 2.8\% $(\mathrm{n}=6)$ worked in a specific area of expertise not related to physical education. Tables 1 and 2 show the participants' knowledge about poliomyelitis and PPS, respectively.

With regard to our questionnaire, we found that professionals who had received previous information about PPS had significantly higher scores than those who had never received information. On average, this difference was approximately $84 \%$ (Figure 1) $(P<0.0001)$.

To demonstrate that the professional experience factor contributes to high performance levels, we correlated performance on the questionnaire and duration of professional activities. We found a statistically significant correlation between experience in the field and scores in our questionnaire $(r=0.1812, P=0.0093)$. Moreover, we found a correlation between education level and scores obtained in the questionnaire $(r=0.2115, P=0.0017)$.

\section{Discussion}

Investigations of the knowledge of physical education professionals about specific diseases are very rare. These types of investigations are important because physical exercise has been considered an important tool for the prevention and treatment of chronic diseases. ${ }^{16,17}$ This is the first study to assess knowledge among physical education professionals about poliomyelitis and PPS. We found that knowledge about poliomyelitis and PPS is low among Brazilian physical education professionals, particularly among those professionals who have had no access to previous information about PPS.
As the majority of surveyed participants had not received any formal education about PPS during their undergraduate degrees $(93.5 \%)$ and $61.8 \%$ did not know about the restrictions on physical activity practice for patients with poliomyelitis sequelae, it is quite plausible that these professionals do not know how to manage a physical exercise program for patients with poliomyelitis sequelae. Thus, physical exercise prescribed by these professionals could be harmful to the health of these patients. The continued education of these professionals should be promoted by public health systems. Similar results have been found for epilepsy ${ }^{13,14}$ and human immunodeficiency virus-positive patients. ${ }^{12}$ For example, Boyle et al ${ }^{12}$ investigated the knowledge of physical education professionals about AIDS and demonstrated that only $22.2 \%$ of professionals had received formal education about AIDS.

Although most professionals had already heard about paralytic poliomyelitis $(95.9 \%)$, they did not have appropriate knowledge about the characteristics of the disease $(38.7 \%$ did not know the etiologic agent and $52.5 \%$ did not know the transmission mode or that a person with sequelae of paralytic poliomyelitis may develop PPS). Only $25.3 \%$ of the respondents had heard of PPS, and only $17.1 \%$ of professionals recognized that a person with sequelae of paralytic poliomyelitis may develop PPS. Consequently, the knowledge of these professionals about the clinical characteristics of PPS was low.

This is not the first study that has demonstrated a low level of knowledge among physical education professionals about a neurologic disease. Vancini et a ${ }^{13,14}$ showed that these professionals did not have accurate knowledge about epilepsy. According to Vancini et al, ${ }^{13,14}$ these results are probably a consequence of two hypotheses, ie, a considerable lack of information and any formal instruction on epilepsy during their graduate study and training, and these professionals not usually being included in a workplace of primary health care, such as health centers, clinics, and hospitals; consequently, they might have less contact with people with epilepsy when compared with physicians and nurses. Therefore, it is reasonable that similar hypotheses can be assumed in our study.

In addition to the general lack of knowledge about PPS and paralytic poliomyelitis, one of the main findings of this study was the fact that there was a positive correlation between education and knowledge of paralytic poliomyelitis and PPS. Professionals who have already obtained information about the disease have a higher level of knowledge than those who have never had access to any information about the disease. These findings can be used to sensitize 
the leaders of public health systems and education to two aspects of PPS education: physical education professionals demonstrate an increase in practical knowledge (at least for this disease) with an increase in education, so these professionals should be encouraged to participate in continuing education programs; and training programs, even those of short duration, may be beneficial for increasing knowledge about PPS among these professionals and most likely among other health professionals as well. Finally, we also demonstrated that more experienced professionals have a greater level of knowledge about poliomyelitis and PPS, possibly because they have already received additional sources of information during their careers, such as participation in congresses, seminars, and scientific meetings, and possibly through higher levels of education.

In conclusion, our study shows that physical education professionals do not have appropriate knowledge about poliomyelitis and PPS. Therefore, the services provided by these professionals may be compromised, and physical exercise prescribed by these professions could harm the patient. Additionally, it is possible that similarly low levels of poliomyelitis and PPS knowledge could be present among other health professionals, including nurses, physiotherapists, physicians, and nutritionists, as demonstrated by Vancini et $\mathrm{l}^{13}$ for epilepsy. Therefore, further studies should be conducted to understand better the knowledge of these professionals about PPS. Public training policies should be implemented to increase knowledge about poliomyelitis and PPS and therefore to improve the services provided to patients.

\section{Author contributions}

CABL contributed to the study concept and design, data acquisition, analysis, interpretation, and manuscript preparation. TMAA, LFPP, and BSS contributed to data acquisition, data analysis, and manuscript preparation. MGS, SABR, and MSA contributed to study concept and design, data analysis, interpretation, and manuscript preparation. RLV contributed to study concept and design, data analysis, interpretation, manuscript preparation, and critical revision of the manuscript.

\section{Acknowledgments}

We would like to thank all of the participants who volunteered their time to participate in the study, which was supported by the Fundação de Amparo à Pesquisa do Estado de Goiás (FAPEG, Brazil; grant number 2009/10267000347). TMAA had a fellowship from the Conselho Nacional de
Desenvolvimento Científico e Tecnológico - Programa Institucional de Bolsas de Iniciação Científica (CNPq/PIBIC, Brazil).

\section{Disclosure}

No commercial party having a direct financial interest in the results of the research presented in this article has or will confer a benefit upon the authors or upon any organization with which the authors are associated.

\section{References}

1. Tiffreau V, Rapin A, Serafi R, et al. Post-polio syndrome and rehabilitation. Ann Phys Rehabil Med. 2010;53:42-50.

2. Ivanyi B, Ongerboer de Visser BW, et al. Macro EMG follow-up study in post-poliomyelitis patients. $J$ Neurol. 1994;242:37-40.

3. Stålberg E, Grimby G. Dynamic electromyography and muscle biopsy changes in a 4-year follow-up: study of patients with a history of polio. Muscle Nerve. 1995;18:699-707.

4. McComas AJ, Quartly C, Griggs RC. Early and late losses of motor units after poliomyelitis. Brain. 1997;120:1415-1421.

5. Rodriguez AA, Agre JC. Correlation of motor units with strength and spectral characteristics in polio survivors and controls. Muscle Nerve. 1991;14:429-434.

6. Wiechers DO, Hubbell SL. Late changes in the motor unit after acute poliomyelitis. Muscle Nerve. 1981;4:524-528.

7. Ivanyi B, Nollet F, Redekop WK, et al. Late onset polio sequelae: disabilities and handicaps in a population-based cohort of the 1956 poliomyelitis outbreak in The Netherlands. Arch Phys Med Rehabil. 1999;80:687-690.

8. Nollet F, Beelen A, Prins MH, et al. Disability and functional assessment in former polio patients with and without postpolio syndrome. Arch Phys Med Rehabil. 1999;80:136-143.

9. Aylward RB, Hull HF, Cochi SL, et al. Disease eradication as a public health strategy: a case study of poliomyelitis eradication. Bull World Health Organ. 2000;78:285-297.

10. World Health Organization. Poliomyelitis. Fact sheet 114. Available from: http://www.who.int/mediacentre/factsheets/fs114/en/. Accessed June 21, 2013.

11. Garber CE, Blissmer B, Deschenes MR, et al. American College of Sports Medicine position stand. Quantity and quality of exercise for developing and maintaining cardiorespiratory, musculoskeletal, and neuromotor fitness in apparently healthy adults: guidance for prescribing exercise. Med Sci Sports Exerc. 2011;43:1334-1359.

12. Boyle M, Sitler M, Kimura I, et al. Knowledge and attitudes of certified athletic trainers in Pennsylvania toward HIV/AIDS and treating HIV-positive athletes. J Athl Train. 1997;32:40-44.

13. Vancini RL, Benedito-Silva AA, Sousa BS, et al. Knowledge about epilepsy among health professionals: a cross-sectional survey in Sao Paulo, Brazil. BMJ Open. 2012;2:e000919.

14. Vancini RL, Lira CA, Gomes da Silva S, et al. Evaluation of physical educators' knowledge about epilepsy. Arq Neuropsiquiatr. 2010;68: 367-371.

15. Kelley K, Clark B, Brown V, et al. Good practice in the conduct and reporting of survey research. Int J Qual Health Care. 2003;15: 261-266.

16. Burns KE, Duffett M, Kho ME, et al. A guide for the design and conduct of self-administered surveys of clinicians. CMAJ. 2008;179: 245-252.

17. Chomistek AK, Cook NR, Flint AJ, et al. Vigorous-intensity leisuretime physical activity and risk of major chronic disease in men. Med Sci Sports Exerc. 2012;44:1898-1905.

18. Morris PJ. Physical activity recommendations for children and adolescents with chronic disease. Curr Sports Med Rep. 2008;7:353-358. 


\section{Publish your work in this journal}

Degenerative Neurological and Neuromuscular Disease is an international, peer-reviewed, open access journal focusing on research into degenerative neurological and neuromuscular disease, identification of therapeutic targets and the optimal use of preventative and integrated treatment interventions to achieve improved outcomes, enhanced

survival and quality of life for the patient. The manuscript management system is completely online and includes a very quick and fair peer-review system. Visit http://www.dovepress.com/testimonials.php to read real quotes from published authors.

Submit your manuscript here: http://www.dovepress.com/degenerative-neurological-and-neuromuscular-disease-journal 